Article

\title{
Chitosan Coating on Silica-Modified Polymethyl Methacrylate for Dental Applications
}

\author{
Mieszko Więckiewicz ${ }^{1, *}$, Eric Wolf ${ }^{2}$, Katarzyna Walczak ${ }^{2}$, Heike Meissner ${ }^{2}$ \\ and Klaus Boening ${ }^{2}$ \\ 1 Department of Experimental Dentistry, Faculty of Dentistry, Wroclaw Medical University, \\ Wroclaw 50-425, Poland \\ 2 Department of Prosthetic Dentistry, Faculty of Medicine, Dresden University of Technology, Dresden 01307, \\ Germany; ericwolf01@t-online.de (E.W.); katarzyna.walczak@uniklinikum-dresden.de (K.W.); \\ heike.meissner@uniklinikum-dresden.de (H.M.); klaus.boening@uniklinikum-dresden.de (K.B.) \\ * Correspondence: m.wieckiewicz@onet.pl; Tel.: +48-660-478-759
}

Received: 16 September 2017; Accepted: 10 October 2017; Published: 13 October 2017

\begin{abstract}
Chitosan is a cationic natural polymer that is widely used as a topical dressing in wound management. Temporary coatings of removable denture bases with chitosan might be useful as supportive treatment in oral medicine. The aim of this study was to analyze the thickness, uniformity, and adhesive strength of chitosan coatings on simulated denture bases made from polymethyl methacrylate (PMMA). According to a standardized protocol, 20 PMMA cylinders (13 mm diameter, $5 \mathrm{~mm}$ in height) as well as 20 cubes $(a=25 \mathrm{~mm}$ ) with intaglio U-shaped profiles were manufactured to simulate average sized alveolar ridges. Cylinders as well as cubes were divided into four test series with $n=5$ each. After sandblasting with silica-modified alumina, one frontal surface of the PMMA cylinders and the intaglio surfaces of the U-shaped profiles was coated with chitosan acetate solution according to the following protocols: one layer of $2 \%$ chitosan acetate solution (test series I), one layer of $4 \%$ chitosan acetate solution (test series II), two layers of $2 \%$ chitosan acetate solution (test series III), and two layers of $4 \%$ chitosan acetate solution (test series IV). After drying and neutralization with $\mathrm{NaOH}$, each cube was cut transversely and the coating thickness across the U-shaped profile assessed with a light microscope. Adhesive strength was evaluated by simulated tooth brushing and the loss of chitosan coating was evaluated qualitatively. Statistical analysis used Friedman ANOVA test for dependent samples and Kruskal-Wallis test for independent samples, post-hoc Dunn's test $(p<0.05)$, and binomial test $(p=0.05)$. The mean chitosan coating thicknesses in the depth of the U-profiles were $71 \mu \mathrm{m}$ (test series I), $77 \mu \mathrm{m}$ (test series II), $121 \mu \mathrm{m}$ (test series III), and $517 \mu \mathrm{m}$ (test series VI). The thickness continuously decreased with rising angulation of the U-profile side walls. In test series I, the chitosan coating thickness significantly dropped above a $30^{\circ}$ angulation of the U-profile side walls. In test series II to IV, the chitosan thickness drop was not statistically significant at angulations of $30^{\circ}$ and $60^{\circ}$, but was at $90^{\circ}$ angulation of the U-profile side walls. Adhesion strength was rated fair to good and did not differ significantly among the four test series. The coating technique described revealed chitosan layers with overall good adhesion strength but differing thicknesses. Coatings with one or two layers of $4 \%$ chitosan acetate solution allowed a relatively uniform chitosan thickness and thus might be usable in oral medicine.
\end{abstract}

Keywords: denture base; PMMA; chitosan; adhesion; coating

\section{Introduction}

Chitosan is an amino-polysaccharide which is obtained from chitin either by chemical or enzymatic $N$-deacetylation [1]. During the deacetylation process, the acetamide bonds of chitin are disrupted acetyl groups removed. The resulting linear chitosan polymer chain is based on 
repetitive D-glucosamine units linked with randomly distributed $N$-acetyl-D-glucosamine units by a 1,4-glycosidic bond [1-3] (Figure 1). Chitosan is biocompatible, hydrophilic, and biodegradable by lysozyme and other enzymes [4-6], but cannot be metabolized by the human digestive tract [3]. In recent years, numerous bio-functional properties of chitosan have been described. As a chemoattractant, chitosan can activate macrophages and neutrophils, stimulate fibroblasts and other human cells, capture growth factors, induce the production of cytokines, and promote angiogenesis $[5,6]$. Chitosan also promotes the process of coagulation and wound healing and may stimulate the formation of granulation tissue and re-epithelialization. Furthermore, partially hydrolyzed chitosan can inhibit the activity and expression of MMP-2 (matrix metalloproteinase 2) in the fibroblasts of human skin [6] and thus reduce the hydrolysis of collagen IV by MMP-2.

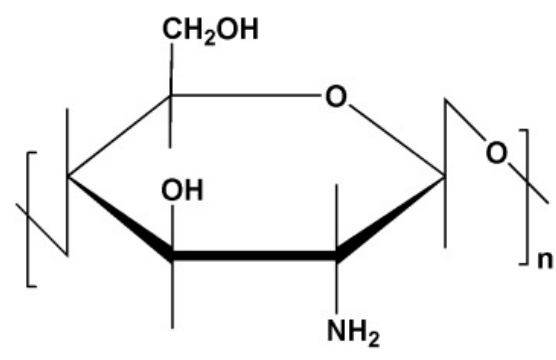

Figure 1. Molecular structure of chitosan.

The specific properties of chitosan open a wide range of applications in the medical field. Specifically, its blood clotting potential [7-9] is of interest. Various manufacturers use chitosan as a key component in wound dressings (i.e., Tricol Biomedical, Portland, OR, USA; Beese Medical, Emmingen-Liptingen, Germany; MedoDerm, Mainz, Germany). So far, little attention has been paid to potential applications of chitosan in oral medicine. Chitosan might be a useful wound dressing to promote coagulation and wound healing in dental surgery, specifically in patients under anticoagulant therapy. Chitosan might also serve as an adjuvant therapeutic agent or as a carrier for pharmaceuticals to treat infections of the oral mucosa [10]. The prevalence of oral mucosa infections induced by dental prostheses (denture stomatitis) is reported to be $15 \%$ to $70 \%$ in populations of elderly removable denture wearers [11,12]. To serve the purposes mentioned above, it might be appropriate to coat intraoral surgical splints or denture bases with chitosan to achieve a permanent close contact of chitosan to the wound surface or the areas of diseased oral mucosa.

Bases of removable dental prostheses are usually made from polymethyl methacrylate (PMMA) (Figure 2). To use PMMA denture bases as a carrier for chitosan requires the adhesion of the hydrophilic chitosan to the hydrophobic PMMA resin surface as well as a predictable thickness of chitosan coatings. A simple technology to achieve the adhesion of chitosan to PMMA has been described in a previous paper [13]. First, the PMMA surfaces are sandblasted at 2.8 bar with $110 \mu \mathrm{m}$ silica-modified alumina (Rocatec Plus Blasting Agent, 3M ESPE, Seefeld, Germany) [14,15]. Due to the high impact energy, the sandblasting process implants silica-modified alumina particles in the relatively soft PMMA resin surface, creating a hydrophilic silica layer [13]. Then, a $2 \%$ acetic chitosan solution is applied to the sandblasted surface and dried in an oven at $45^{\circ} \mathrm{C}$ for $120 \mathrm{~min}$. The dried chitosan coating is then neutralized in 1 molar $\mathrm{NaOH}$ and subsequently rinsed in distilled water. These experiments were conducted on flat PMMA specimen surfaces. Real life removable denture bases follow the contour of the edentulous alveolar ridges and thus are curved.

This study investigated the application of uniform chitosan coatings on intaglio surfaces of curved dentures bases by modifying the method described above [13]. Variables were the concentration of the acetic chitosan solution ( $2 \%$ and $4 \%$ ) and the application of one or two consecutively applied layers of acetic chitosan solution, resulting in four different coating procedures. Besides uniformity and predictable thickness, the adhesion strength of chitosan was of interest, as the coatings should 
withstand denture cleansing by tooth brushing. Thus, the adhesive strength of chitosan to PMMA was assessed qualitatively in each coating procedure. The following five null hypotheses were stated using specimens simulating the curvature of intaglio denture base surfaces on which uniform thicknesses of chitosan coatings can be achieved when applying:

- One layer of $2 \%$ acetate chitosan solution;

- One layer of $4 \%$ acetate chitosan solution;

- Two layers of $2 \%$ acetate chitosan solution applied consecutively with intermediate drying and neutralization;

- Two layers of $4 \%$ acetate chitosan solution applied consecutively with intermediate drying and neutralization;

- The adhesive strength of all four chitosan coating procedures is sufficient to withstand usual mechanical measures of denture cleansing.

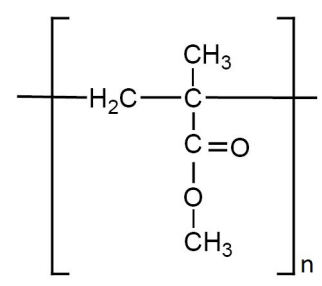

Figure 2. Molecular structure of polymethyl methacrylate. It is a hydrocarbon chain with $\mathrm{CH}_{3}$ and $\mathrm{COOCH}_{3}$ groups at the sides.

\section{Materials and Methods}

Two different chitosan solutions were prepared both using $2 \%$ acetic acid obtained from the Hospital pharmacy of the Carl Gustav Carus University Hospital (Dresden University of Technology, Dresden, Germany). One solution contained $2 \%$ chitosan the second solution contained $4 \%$ chitosan. Chitosan was dissolved in acetic acid at a temperature of $60^{\circ} \mathrm{C}$ using a magnetic stirrer (RET CV S000, IKA-Werke, Staufen, Germany). After preparation, the solutions were stored in a refrigerator at $6{ }^{\circ} \mathrm{C}$ for $24 \mathrm{~h}$ until use.

Twenty PMMA cubes (edge length $25 \mathrm{~mm}$ ) with intaglio U-shaped profiles were manufactured according to a standardized protocol (Figure 3). The intaglio U-shaped profiles corresponded in their dimensions to average sized alveolar ridges $[16,17]$ with the purpose of simulating the shape of intaglio removable denture surfaces. All cubes were made from PMMA (Palapress, Heraeus-Kulzer, Hanau, Germany) according to manufacturer's instructions (powder to liquid ratio $10 \mathrm{~g}$ to $7 \mathrm{~mL}$, mixing time $15 \mathrm{~s}$ at $23^{\circ} \mathrm{C}$ ). The resin was poured into a casting mold within a period of two minutes and polymerized for $20 \mathrm{~min}$ at $55^{\circ} \mathrm{C}$ and $2.5 \mathrm{bar}$ pressure. After polymerization, all surfaces were smoothed with 1000 grit sandpaper. Additionally, 20 PMMA cylinders ( $13 \mathrm{~mm}$ in diameter, $5 \mathrm{~mm}$ in height) were manufactured similarly to the above procedure. The mixed resin was poured into a casting mold and covered with a glass plate to ensure a smooth frontal surface (Figure 4).

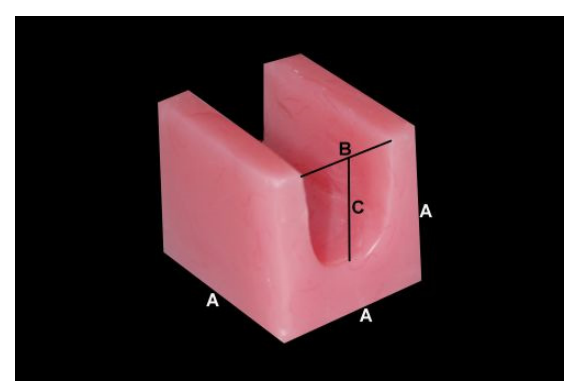

Figure 3. Square specimen with U-shaped profile made from PMMA $(A=25 \mathrm{~mm}, B=13 \mathrm{~mm}, C=18 \mathrm{~mm})$. 


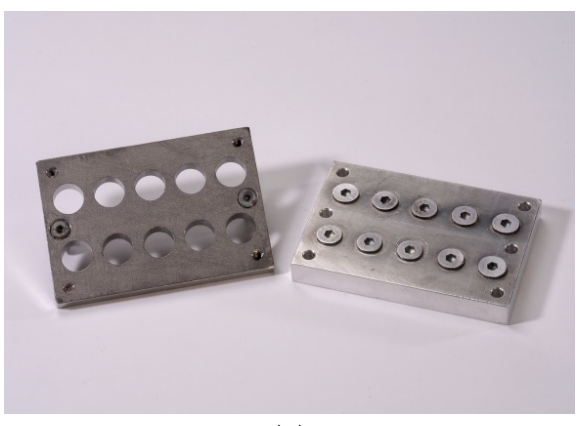

(a)

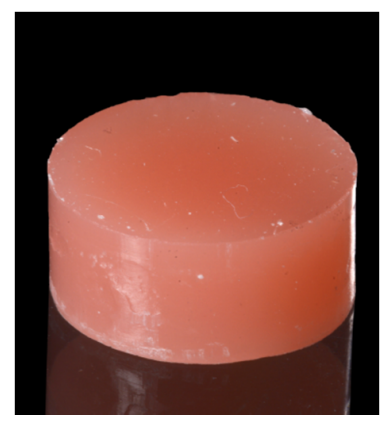

(b)

Figure 4. (a) Casting mold for PMMA cylinders and (b) PMMA cylinder after polymerization.

Both PMMA cylinders and cubes were divided into four test series with five specimens each. Within the cubes the intaglio U-profile surfaces were coated with chitosan, whereas on the cylinders chitosan coatings were carried out on the frontal surfaces that were cured against the glass plate. Chitosan coatings in the four test series comprised one of the following protocols:

Protocol test series I:

- Sandblasting with Rocatec Plus;

- Coating with $2 \%$ acetic chitosan solution using a soft brush;

- $\quad$ Storage in a drying oven $\left(120 \mathrm{~min}, 45^{\circ} \mathrm{C}\right)$;

- Neutralization with $1 \mathrm{~mol} \mathrm{NaOH}(5 \mathrm{~min})$;

- Immersion in aqua dest. for $10 \mathrm{~min}$.

Protocol test series II:

As test series I, but $4 \%$ acetic chitosan solution.

Protocol test series III:

- Sandblasting with Rocatec Plus;

- Coating with $2 \%$ acetic chitosan solution using a soft brush;

- Storage in a drying oven $\left(120 \mathrm{~min}, 45^{\circ} \mathrm{C}\right)$;

- Neutralization with $1 \mathrm{~mol} \mathrm{NaOH}$ (5 min);

- Immersion in aqua dest. for $10 \mathrm{~min}$;

- Air drying for $120 \mathrm{~min}$;

- Coating with second layer $2 \%$ acetic chitosan solution using a soft brush;

- Immobilization of the coating by immersion in $1 \mathrm{~mol} \mathrm{NaOH}$ (5 min);

- Immersion in aqua dest. for $10 \mathrm{~min}$;

- $\quad$ Storage in a drying oven $\left(120 \mathrm{~min}, 45^{\circ} \mathrm{C}\right)$;

- Immersion in aqua dest. for $10 \mathrm{~min}$.

Protocol test series IV:

As test series III, but $4 \%$ acetic chitosan solution for both coatings.

\subsection{Measurement of Chitosan Coating Thickness}

After finishing the coating procedures, each cube was wrapped with adhesive tape and the intaglio chitosan coated U-profiles were poured with dental stone (Figure 5). After setting, a slice of $5 \mathrm{~mm}$ thickness was cut from the center of each cube. A final wet polishing of the cut surfaces was done on a 
Rotopol 22 polisher (Struers, Rodovre, Denmark) using waterproof silicon carbide paper disks (Struers) with decreasing grain sizes until 1000 grit sand paper. For each specimen, the thickness of the chitosan coating was assessed on both sides of the cut slices using a Leica MZ12 light microscope (Meyer Instruments, Houston, TX, USA) at a magnification of $\times 63$ in seven measuring points. Measurements started at the depth of the U-shaped profile and then continued on both ascending side walls (Figure 6). Three measurements were done on each point of both sides. An average value was calculated from the six single measurements for each measuring point. On both side walls distances between the measuring points were $3.5 \mathrm{~mm}$ which corresponds to a $0^{\circ}, 30^{\circ}, 60^{\circ}$, and $90^{\circ}$ angulation from the horizontal axis of the U-profile (Figure 6).

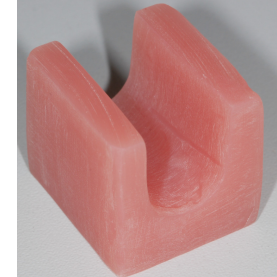

(a)

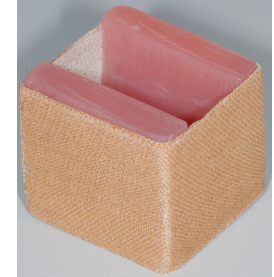

(b)

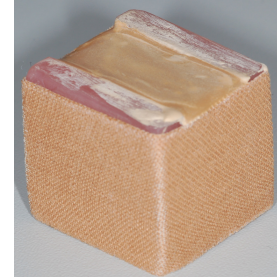

(c)

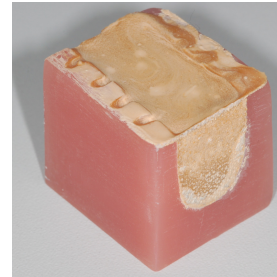

(d)

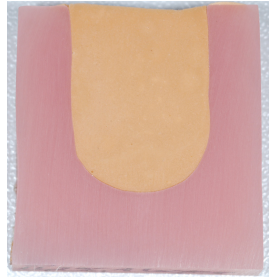

(e)

Figure 5. Specimen preparation for light microscopic measurements of chitosan coating thickness: (a) coating with chitosan; (b) wrapping with adhesive tape; (c) filling with stone; (d) removal of tape; (e) tranversal cutting.
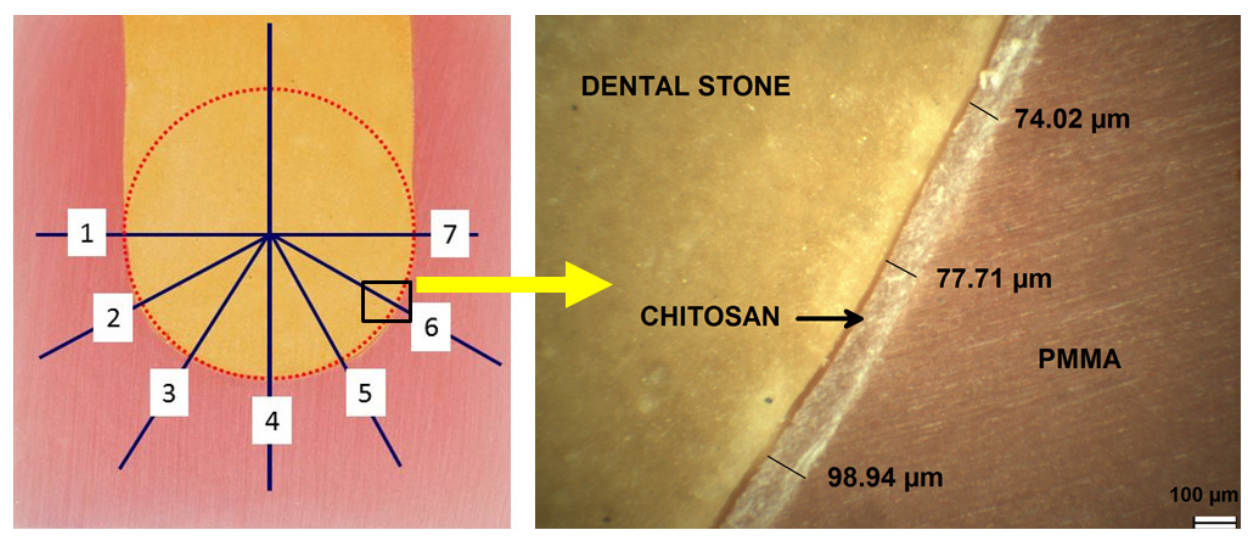

Figure 6. Measuring points to assess chitosan coating thickness at the depth of the U-shaped profile (4) and the ascending sides at $30^{\circ}(3,5), 60^{\circ}(2,6)$, and $90^{\circ}$ angulation $(1,7)$; light microscopic picture.

\subsection{Determination of Chitosan Adhesion Strength to PMMA}

The assessment of adhesion strength between chitosan and PMMA was conducted qualitatively with a standard hand toothbrush (Oral B 35, medium hardness, Blend-a-Med, Schwalbach, Germany) and 100 strokes by hand to simulate average denture base cleansing by tooth brushing over an estimated one-week period. The chitosan coatings (Figure 7a) were wetted with tap water; no tooth paste or other abrasive agent was used. The adhesion strength then was assessed according to one of the following four scores:

Score 0: no adhesion—chitosan coating peels off when brushing (Figure $7 \mathrm{~b}$ ).

Score 1: low adhesion - chitosan coating can be removed at least in part by average force brushing (Figure 7c).

Score 2: fair adhesion—chitosan coating can be removed at least in part by forceful brushing only (Figure 7c).

Score 3: good adhesion—chitosan coating could not be removed even by forceful brushing (Figure $7 \mathrm{~d}$ ). 


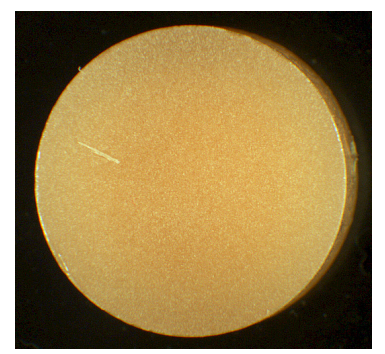

(a)

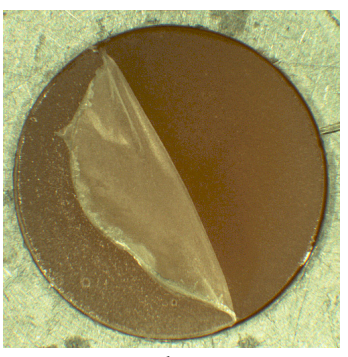

(b)

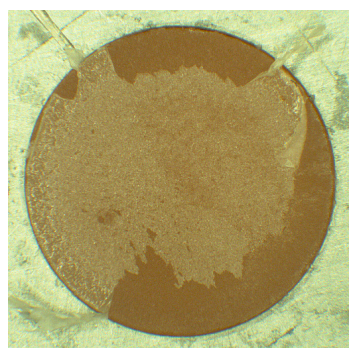

(c)

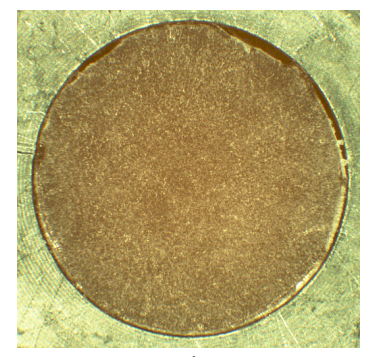

(d)

Figure 7. Valuation and scoring of adhesion strength between chitosan coating and PMMA surface: (a) PMMA specimen after chitosan coating; (b) no adhesion of chitosan coating; (c) low/fair adhesion after brushing; (d) good adhesion after brushing.

\subsection{Statistical Analysis}

The achieved data concerning thickness showed the schedule of repeated measurements with additional factors. This type of experiment suggests carrying mixed design ANOVA. Analysis of the data showed that they did not meet the assumptions required faced to perform the abovementioned test (e.g., sphericity, normality scheduled in each group, homogeneity of variance). Because of this, for comparisons between particular groups the statistical analysis was performed using the Friedman ANOVA test for dependent samples and Kruskal-Wallis test for independent samples followed by post-hoc Dunn's test $(p<0.05)$. For statistical analysis of the presence of adhesion, the binomial test was used $(p=0.05)$.

\section{Results}

\subsection{Measurement of Chitosan Coating Thickness}

Overall coating thicknesses of chitosan in the U-shaped profiles ranged from 15 to $538 \mu \mathrm{m}$. Mean values of each test series and results of the statistical analysis are presented in Table 1 . In test series I, the mean thickness of the chitosan coating was $71 \mu \mathrm{m}$ at the depth of the U-shaped profile (point 4 in Figure 6) and dropped to 15 and $16 \mu \mathrm{m}$, respectively, at the side walls of the U-profiles at $90^{\circ}$ inclination (points 1 and 7 in Table 1 and Figure 6). The chitosan coating thickness at measuring point 4 was significantly higher than the thicknesses obtained from the inclined side walls at measuring points 2 and $6\left(60^{\circ}\right.$ angulation) as well as measuring points 1 and $7\left(90^{\circ}\right.$ angulation $)(p<0.01)$. The chitosan coating thickness at measuring point 4 did not differ significantly from measuring points 3 and 5 at $30^{\circ}$ angulation.

Also, in test series II, measuring points 1 and 7 showed the lowest mean thickness of chitosan coatings ( 34 and $40 \mu \mathrm{m}$ ). These thicknesses were significantly lower than the mean chitosan coating thickness at measuring point 4 (depth of the U-profile) $(p<0.01)$. Measuring points 2 to 6 did not differ significantly from measuring point 4 (Table 1).

In both test series III and IV, measuring points 1 and 7 exhibited significantly lower mean thicknesses compared to their corresponding measuring points 4 (depth of the U-profile). In both test series, the chitosan coating thickness in measuring points 6 differed significantly from their corresponding measuring points $4(p<0.01)$ while measuring points $2,3,4$, and 5 within both test series showed no significant differences in chitosan coating thicknesses.

Statistical analysis of coating thicknesses of identical measuring points between the four test series revealed significant differences in all seven measuring points in test series I versus II, III, and IV. Significant differences in all seven measuring points were also found in test series II versus IV and test series III versus IV. When analyzing test series II versus III, only measuring points 4 (depth of the U-profile) differed significantly. 
Table 1. Measured chitosan thickness ( $\mu \mathrm{m}$; mean/SD). Asterisks $\left(^{*}\right)$ indicate similar measuring points between the four test series that were not statistically significantly different. Superscript crosses $\left(^{+}\right)$ indicate measuring points within each test series were statistically significantly different from the center of the U-profile (measuring point 4).

\begin{tabular}{ccccccccc}
\hline & \multirow{8}{*}{$\begin{array}{c}\text { Chitosan } \\
\text { Test Series }\end{array}$} & \multicolumn{7}{c}{$\begin{array}{c}\text { Measuring Points at the U-Profile } \\
\text { (Angulation) }\end{array}$} \\
\cline { 3 - 9 } & $\begin{array}{c}\text { Contration } \\
\mathbf{( \% )}\end{array}$ & $\mathbf{1}$ & $\mathbf{2}$ & $\mathbf{3}$ & $\mathbf{4}$ & $\mathbf{5}$ & $\mathbf{6}$ & $\mathbf{7}$ \\
& & $\left.\mathbf{( 9 0}^{\circ}\right)$ & $\left.\mathbf{( 6 0}^{\circ}\right)$ & $\left.\mathbf{( 3 0}^{\circ}\right)$ & $\left.\mathbf{( 0}^{\circ}\right)$ & $\left.\mathbf{( 3 0}^{\circ}\right)$ & $\left.\mathbf{( 6 0}^{\circ}\right)$ & $\left.\mathbf{( 9 0}^{\circ}\right)$ \\
\hline I & 2 & $16 / 6^{+}$ & $29 / 11^{+}$ & $39 / 10$ & $71 / 38^{*}$ & $38 / 9$ & $34 / 14^{+}$ & $15 / 5^{+}$ \\
II & 4 & $34 / 19^{*,+}$ & $80 / 20^{*}$ & $85 / 13^{*}$ & $77 / 16^{*}$ & $81 / 14^{*}$ & $77 / 19^{*}$ & $40 / 15^{*,+}$ \\
III & $2+2$ & $48 / 15^{*++}$ & $101 / 48^{*}$ & $124 / 48^{*}$ & $121 / 45$ & $122 / 43^{*}$ & $87 / 34^{*,+}$ & $41 / 15^{*,+}$ \\
IV & $4+4$ & $237 / 83^{+}$ & $448 / 180$ & $538 / 203$ & $517 / 214$ & $499 / 158$ & $317 / 111^{+}$ & $161 / 66^{+}$ \\
\hline
\end{tabular}

\subsection{Determination of the Quality of Chitosan Coating Adhesion to PMMA}

In all four test series, the adhesion strength between chitosan coatings and PMMA were rated either score 2 (fair adherence, Figure 5c) or score 3 (good adherence, Figure 5d) (Table 2). Median scores were 3 in test series I to III and 2 in test series IV. The binomial test did not reveal any statistically significant differences between the scoring in the four test series $(p>0.1)$.

Table 2. Scoring of the adhesion strength of chitosan to the underlying PMMA.

\begin{tabular}{ccccccc}
\hline & \multirow{2}{*}{$\begin{array}{c}\text { Chitosan } \\
\text { Test Series }\end{array}$} & \multicolumn{5}{c}{ Specimen \# } \\
\cline { 3 - 6 } & $\begin{array}{c}\text { Concentration } \\
\mathbf{( \% )}\end{array}$ & $\mathbf{1}$ & $\mathbf{2}$ & $\mathbf{3}$ & $\mathbf{4}$ & $\mathbf{5}$ \\
\cline { 3 - 6 } & 2 & 3 & 3 & 3 & 3 & 3 \\
I & 4 & 3 & 3 & 3 & 2 & 2 \\
II & $2+2$ & 3 & 2 & 2 & 3 & 3 \\
III & $4+4$ & 2 & 3 & 3 & 2 & 2 \\
IV & & &
\end{tabular}

\section{Discussion}

Chitosan coatings temporarily applied to intaglio surfaces of removable denture bases may be useful to promote blood clotting or wound healing after alveolar surgical procedures. Furthermore, chitosan coatings might serve as a carrier for topical administration of pharmaceutics [10]. If used for the purposes mentioned above, chitosan coating techniques should allow a predictable thickness and should adhere reliably to the denture base for the timeframe needed. This study investigated the applicability of a simple technology to provide chitosan coatings on bases of complete or partial removable dentures made from PMMA resin.

Alveolar bone resorption in the edentulous jaw is a common clinical problem. Tooth loss triggers biological events that result in irreversible bone resorption, involving both horizontal and vertical reduction, and result in a progressive flattening of the alveolar ridges [18]. However, rather frequently, removable dentures are inserted immediately after tooth extraction to preserve esthetics, speech, and jaw relation, as well as to protect the alveolar coagulum. The U-shaped profiles in this study with side walls up to $90^{\circ}$ angulation simulated the geometry of well-preserved alveolar ridges as they might be expected when extracting broken down teeth [16,17].

As shown in Table 1, none of the four test series produced chitosan coatings of uniform thickness across the entire U-profile from measuring points 1 to 7 . Thus, the null hypotheses 1 to 4 had to be rejected. Test series I revealed insignificant changes in chitosan coating thickness between measuring points 3 and 5 only. Between the timespan of chitosan coating and the drying process, the acetic chitosan solution flows towards the depth of the U-profile following the laws of gravity.

To meet this problem, the chitosan solution viscosity was increased. While the $2 \%$ acetic chitosan solution is of a syrupy, fairly moderate viscosity, the high viscosity of the $4 \%$ solution took the torque 
of the stirrers (RET CV S000, IKA-Werke) to the limits. Thus, a 4\% acetic solution marked the upper limit of the experiments concerning viscosity. The $4 \%$ acetic chitosan solution in test series II indeed allowed a more uniform chitosan coating thickness, with continuously insignificant differences in chitosan coating thickness from measuring point 2 to 6 ( $60^{\circ}$ angulation). Concerning clinical relevance, a coating such as that achieved in series II might not completely embrace a well-preserved alveolar ridge, but most likely will cover the entire alveolar wound surface after a tooth extraction. Thus, a uniform coating thickness to a $60^{\circ}$ angulation might be judged clinically satisfactorily to serve as a wound dressing. However, it is doubtful whether the low chitosan coating thickness averaging between 77 and $85 \mu \mathrm{m}$ (Table 1) would be therapeutically sufficient. The two-step coating procedures test series III and IV showed good adhesion to the PMMA substructure as well as a coating thickness up to $500 \mu \mathrm{m}$. Surprisingly, in both test series III and IV, chitosan coating thicknesses were found to be asymmetric despite the fully symmetric U-profiles with measuring points mirroring each other. Probably this asymmetry was due to an investigator's lack of experience. Obviously, coating by hand requires a learning curve even for professionals in the field of dentistry.

A second approach was to immobilize the acetic chitosan solution by immersing the coated specimens in $\mathrm{NaOH}$ immediately after application. In the neutralized environment, the chitosan molecule chains become insoluble and the viscous solution turns into a gel. In preliminary tests, immersion in 1 molar $\mathrm{NaOH}$ for 5 min proved to be highly effective to immobilize the acetic chitosan solution. However, after drying, the previously neutralized chitosan gel showed no adhesion to the silica-modified PMMA surface (score 0, Figure 7b). Clearly, the acidic environment during the drying process is essential for the molecular interaction to achieve adhesion between chitosan and the silica-modified PMMA surface. On the other hand, neutralization by $\mathrm{NaOH}$ after a completed drying process did not impair adhesion.

A previous study described in detail the process to achieve adhering chitosan coatings on PMMA surfaces [13]. In the first step, the PMMA surfaces were sandblasted with a 110-micron silica-modified alumina oxide (Rocatec Plus blasting agent, 3M ESPE, Seefeld, Germany) at 2.8 bar (Figure 8a). In preliminary tests, sandblasting was carried out under identical conditions using alumina oxide of similar shape and grain size without and with silica-modified surface (Rocatec Pre/Rocatec Plus blasting agent, 3M ESPE). Average roughness $R_{\mathrm{a}}$ and mean roughness depth $R_{\mathrm{z}}$ on the PMMA specimens were analyzed using a surface profiler Hommel Etamic W20 (JENOPTIK Industrial Metrology $\mathrm{GmbH}$, Villingen-Schwenningen, Germany) at a crosshead speed of $0.5 \mathrm{~mm} / \mathrm{s}$. No differences in surface roughness were found (Table 3). However, adhesion of chitosan to PMMA was achieved with the silica-modified sandblasting agent only. Thus, micro-mechanic retention cannot be considered a key factor when explaining the adhesion between chitosan and PMMA. Scanning electron microscopic images detected blasting agent particles impacted in the resin surface after sandblasting (Figure 8b,c).

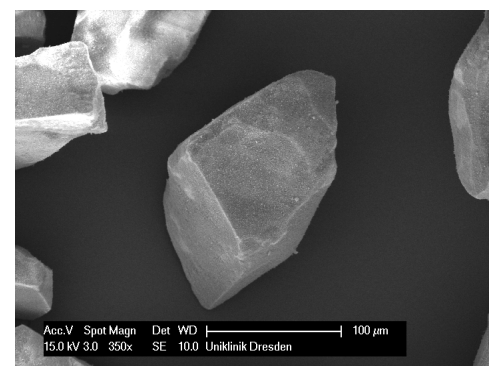

(a)

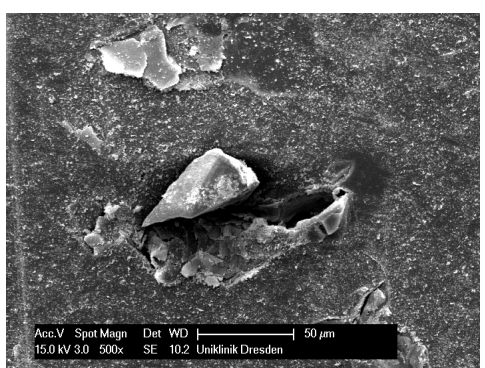

(b)

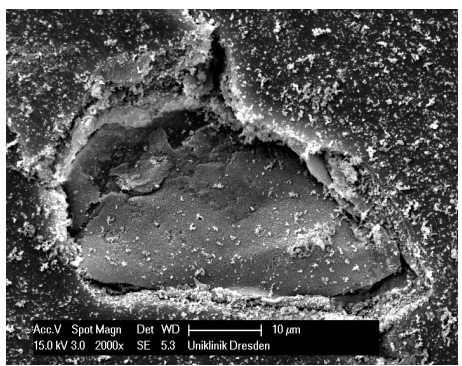

(c)

Figure 8. (a) Sandblasting agent (Rocatec Plus); (b,c) SEM images of impacted particles after sandblasting of PMMA resin surfaces. 
Table 3. Surface roughness $R_{\mathrm{a}}$ and $R_{\mathrm{z}}$ before and after the sandblasting of PMMA specimens $(n=10)$. The results for Rocatec Pre and Rocatec Plus blasting agent did not exhibit statistically significant differences. (U-Test, $p=0.05$ ).

\begin{tabular}{cccc}
\hline Surface Roughness & Before Sandblasting & Rocatec Pre Blasting Agent & Rocatec Plus Blasting Agent \\
\hline$R_{\mathrm{a}}($ mean $/ \mathrm{DS})$ & $0.04 / 0.01$ & $3.04 / 0.32$ & $2.98 / 0.09$ \\
$R_{\mathrm{Z}}$ (mean/DS) & $0.30 / 0.07$ & $20.92 / 1.25$ & $19.57 / 1.08$ \\
\hline
\end{tabular}

In an acidic environment $(\mathrm{pH}<6.5)$, the negatively charged $\mathrm{Si}-\mathrm{OH}$ groups at the silica surface of the impacted Rocatec Plus blasting agent interact with the protonated chitosan amino groups $\left(\mathrm{NH}_{3}{ }^{+}\right)$by electrostatic attraction forces and dipole-dipole interactions [19-22]. The close molecular proximity may induce other secondary valence forces such as van der Waal forces or hydrogen bonds $[23,24]$. This hypothesis is supported by the observation that no adhesion occurred when the acetic chitosan solution was neutralized by $\mathrm{NaOH}$ prior to drying the process [13]. The amino groups of the chitosan molecules lose their positive charge and do not interact with the hydroxyl groups at the silica surface [25]. However, once adhesion was established after finishing the drying process, neutralization with $\mathrm{NaOH}$ did not impair the adhesion of chitosan to PMMA. Figure 9 shows the close contact between PMMA and chitosan after drying and neutralization.

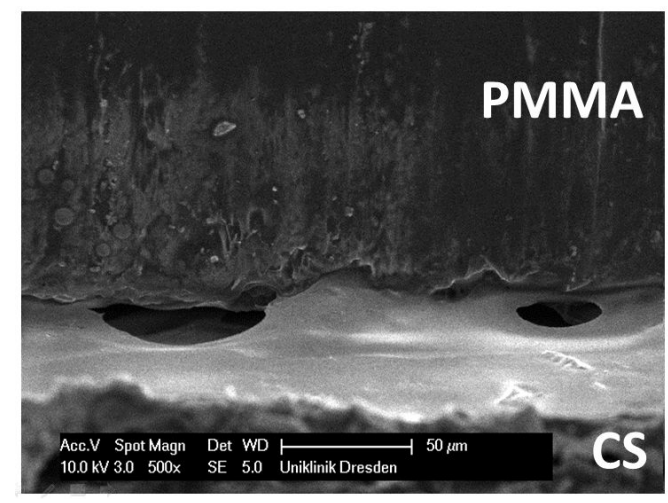

(a)

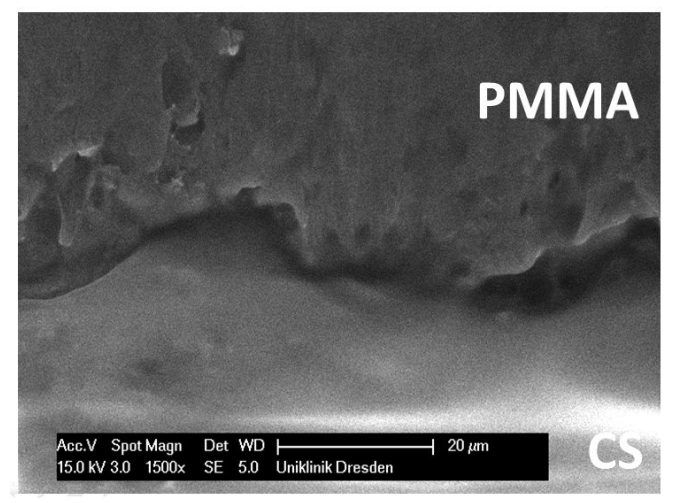

(b)

Figure 9. Scanning electron microscope images showing the morphology at the chitosan/PMMA interface after coating with $4 \%$ acetic chitosan solution (a). Despite its high viscosity, the adhering chitosan layer is in direct proximity to the sandblasted PMMA substructure following peaks and valleys of the surface roughness profile $(\mathbf{b})$. The voids at the chitosan/PMMA interface are probably a result of moisture loss while evacuating the SEM chamber and heating by the electron beam.

Other studies confirmed the mechanism of molecular interaction between chitosan and silica by infrared spectroscopy [26-28]. El-Barghouthi et al. [28] investigated chitosan-silicate co-precipitates derived from colloidal silicon dioxide suspensions. In their study, chitosan-silica processing was basically a precipitation of the partially negatively charged silica onto the positively charged chitosan. Comparisons of the FTIR spectra of chitosan, silica, and chitosan-silica co-precipitate did not represent a chemical reaction type. Without evidence of covalent bonding and ionic interactions, the authors concluded that silica ions interact with the glucopyranose rings of chitosan, presumably through dipole-dipole and hydrogen-bonding interactions. Thus, hydrogen bonds might be a key factor to explain the adhesion between chitosan and the silica-modified PMMA surface. Hydrogen bonds preferentially occur between hydroxyl- $(\mathrm{OH})$, carbonyl- $(\mathrm{C}=\mathrm{O})$, carboxyl- $(\mathrm{COOH})$, as well as amino$\left(\mathrm{NH}_{2}\right)$ groups $[29,30]$. Due to their relatively high number of hydroxyl and amino groups, chitosan molecules exhibit an affinity to hydroxyl groups and silicon compounds [31,32]. Physical properties in cellulose crucially depend on hydrogen bonds, a biopolymer closely related to chitosan [33]. 
Nanoarchitectonics is a rather new concept in research with the intention to arrange structural units in specific configurations on a molecular level. Within the wide range of applications in nanoarchitectonics, one promising field is the controlled topical drug delivery by specifically tailored nanoparticles [34,35]. It is widely accepted that the topical use of chitosan nanoparticles may improve drug bioavailability by prolonging the residence time of drugs applied [36]. Thus, the development of sustained release systems based on chitosan for controlled oral mucosal delivery of chlorhexidine is one focus in current research [37]. Chitosan coatings applied to removable denture bases or intraoral splints may be loaded with prefabricated drugs containing chitosan nano- or microparticles. The coatings retain the formulation at the site of administration, improving drug absorption and bioavailability.

In a study on an elderly group of 375 denture wearers, the use of tooth brushes and water was the most common measure of daily denture cleansing [38]. Therefore, the assessment of adhesion strength between chitosan and PMMA in this study was conducted qualitatively under tap water using a standard hand toothbrush. One hundred strokes of brushing simulated roughly a one-week period, which is a common time frame to prescribe topical medications in denture stomatitis $[39,40]$. Adhesion strength was rated either score 2 (fair adhesion-chitosan coating can be removed at least in part by forceful tooth brushing only) or score 3 (good adhesion-chitosan coating could not be removed even by forceful tooth brushing) without any significant differences among the four test series. Thus, null hypothesis 5 was supported and the adhesive strength of chitosan coatings on denture base surfaces made from PMMA might be considered clinically sufficient.

The method described to coat PMMA denture bases with chitosan involves standard equipment of a dental laboratory. Adhesive coatings of chitosan to PMMA do not require any further organic or inorganic coupling agents that might interfere with the human physiology. Rocatec Plus blasting agent contains aluminum oxide and silica. It was introduced in dental technology in 1984 [41], and has since been used widely, even for intraoral repairs in fixed dental prostheses [42]. So far, no adverse health effects have been reported in the literature.

More sophisticated methods such as a constant three-dimensional rotation of the prostheses during the drying process might have been taken into consideration to achieve more uniform chitosan coatings. However, if chitosan coatings prove to be beneficial in oral medicine, the technology should be cost effective. Thus, the procedures in this study were limited intentionally to simple measures and standard armamentarium of the dental laboratory.

\section{Conclusions}

Within the limits of this study, it is concluded that intaglio surfaces of PMMA denture bases may be coated with chitosan layers with fairly uniform thickness when using a highly viscous $4 \%$ acetic chitosan solution. Current preliminary experiments show that the above method works equally well on chitosan derivatives such as chitosan-acetate, -lactate, -glutamate, and -hydrochloride. Whether or not chitosan or chitosan-derivative denture base coatings in general are as effective as hemostatic or antimicrobial agents is not yet known and will be subject to clinical research. However, before conducting clinical studies, additional preclinical data are needed to obtain approval from an ethics committee, such as data on the potential degradation of chitosan coatings by dental disinfectants. Assessment of the adhesive strength of chitosan coatings to PMMA surfaces was limited to the use of toothbrush and tap water. Potential adverse effects of ultrasonic denture cleansing units, denture cleaning tablets, or disinfecting mouth rinses on chitosan adhesion should be subject to further research.

Acknowledgments: This paper is part of research project supported by the Forschungsgemeinschaft Dental e.V. (German Research Foundation Dentistry, Grant\# FV 2/2014) and the Open Access Publication Funds of the TU Dresden.

Author Contributions: Mieszko Więckiewicz and Klaus Boening conceived and designed the experiment. All authors performed the experiment. Mieszko Wieckiewicz and Klaus Boening analyzed the data. Mieszko Wieckiewicz coordinated the writing of the manuscript. Klaus Boening ultimately revised the paper before submission.

Conflicts of Interest: The authors declare no conflict of interest. 


\section{References}

1. Rinaudo, M. Chitin and chitosan: Properties and applications. Prog. Polym. Sci. 2006, 31, 603-632. [CrossRef]

2. Kumar, M.N.V.R. A review of chitin and chitosan applications. React. Func. Polym. 2000, 46, 1-27. [CrossRef]

3. Zhao, Y.; Park, R.D.; Muzzarelli, R.A.A. Chitin deacetylases: Properties and applications. Mar. Drugs 2010, 8, 24-46. [CrossRef] [PubMed]

4. Kumar, M.N.; Muzzarelli, R.A.A.; Muzzarelli, C.; Sashiwa, H.; Domb, A.J. Chitosan chemistry and pharmaceutical perspectives. Chem. Rev. 2004, 104, 6017-6084. [CrossRef] [PubMed]

5. Muzzarelli, R.A.A.; Muzzarelli, C. Chitosan chemistry: Relevance to the biomedical sciences. Adv. Polym. Sci. 2005, 186, 151-209.

6. Muzzarelli, R.A.A. Chitins and chitosans for the repair of wounded skin, nerve, cartilage and bone. Carbohydr. Polymers 2009, 76, 167-182.

7. Brown, M.A.; Daya, M.R.; Worley, J.A. Experience with chitosan dressings in a civilian EMS system. J. Emerg. Med. 2009, 37, 1-7. [CrossRef] [PubMed]

8. Pusateri, A.E.; McCarthy, S.J.; Gregory, K.W.; Harris, R.A.; Cardenas, L.; McManus, A.T.; Goodwin, C.W., Jr. Effect of a chitosan-based hemostatic dressing on blood loss and survival in a model of severe venous hemorrhage and hepatic injury in swine. J. Trauma 2003, 54, 177-182. [CrossRef] [PubMed]

9. Wedmore, I.; McManus, J.G.; Pusateri, A.E.; Holcomb, J.B. A special report on the chitosan-based hemostatic dressing: Experience in current combat operations. J. Trauma 2006, 60, 655-658. [CrossRef] [PubMed]

10. Senel, S.; Ikinci, G.; Kaş, S.; Yousefi-Rad, A.; Sargon, M.F.; Hincal, A.A. Chitosan films and hydrogels of chlorhexidine gluconate for oral mucosal delivery. Int. J. Pharm. 2000, 193, 197-203. [CrossRef]

11. Salerno, C.; Pascale, M.; Contaldo, M.; Esposito, V.; Busciolano, M.; Milillo, L.; Guida, A.; Petruzzi, M.; Serpico, R. Candida-associated denture stomatitis. Med. Oral Patol. Oral Cir. Bucal 2011, 16, 139-143. [CrossRef]

12. Gendreau, L.; Loewy, Z.G. Epidemiology and etiology of denture stomatitis. J. Prosthodont. 2011, 20, 251-260. [CrossRef] [PubMed]

13. Wieckiewicz, M.; Wolf, E.; Richter, G.; Meissner, H.; Boening, K. New concept of polymethyl methacrylate (PMMA) and polyethylene terephthalate (PET) surface coating by chitosan. Polymers 2016, 8, 132. [CrossRef]

14. Kern, M.; van Thompson, V.P. Sandblasting and silica coating of a glass-infiltrated alumina ceramic: Volume loss, morphology, and changes in the surface composition. J. Prosthet. Dent. 1994, 71, 453-461. [CrossRef]

15. Robina, C.; Scherrera, S.S.; Wiskotta, H.W.A.; de Rijkb, W.G.; Belsera, U.C. Weibull parameters of composite resin bond strengths to porcelain and noble alloy using the Rocatec system. Dent. Mater. 2002, 18, 389-395. [CrossRef]

16. Katsoulis, J.; Enkling, N.; Takeichi, T.; Urban, I.; Mericske-Stein, R.; Avrampou, M. Relatively bone width of the edentulous maxillary ridge. Clinical implications of digital assessment in presurgical implant planning. Clin. Implant. Dent. Relat. Res. 2012, 14, 213-223. [CrossRef] [PubMed]

17. Ural, C.; Bereket, C.; Sener, I.; Aktan, A.M.; Akpinar, Y.Z. Bone Height measurement of maxillary and mandibular bones in panoramic radiographs of edentulous patients. J. Clin. Exp. Dent. 2011, 3, 5-9. [CrossRef]

18. Van der Weijden, F.; Dell'Acqua, F.; Slot, D.E. Alveolar bone dimensional changes of post-extraction sockets in humans: A systematic review. J. Clin. Periodontol. 2009, 36, 1048-1058. [CrossRef] [PubMed]

19. Liu, Y.L.; Su, Y.H.; Lai, J.Y. In situ crosslinking of chitosan and formation of chitosan-silica hybrid membranes with using $\gamma$-glycidoxypropyltrimethoxysilane as a crosslinking agent. Polymer 2004, 45, 6831-6837. [CrossRef]

20. Rashidova, S.S.; Shakarova, D.S.; Ruzimuradov, O.N.; Satubaldieva, D.T.; Zalyalieva, S.V.; Shpigun, O.A.; Varlamov, V.P.; Kabulov, B.D. Bionanocompositional chitosan-silica sorbent for liquid chromatography. J. Chromatogr. B 2004, 800, 49-53. [CrossRef]

21. Liu, Y.L.; Su, Y.H.; Lee, K.R.; Lai, J.Y. Crosslinked organic-inorganic hybrid chitosan membranes for pervaporation dehydration of isopropanol-water mixtures with a long-term stability. J. Membr. Sci. 2005, 251, 233-238. [CrossRef]

22. Shirosaki, Y.; Tsuru, K.; Hayakawa, S.; Osaka, A.; Lopes, M.A.; Santos, J.D.; Costa, M.A.; Fernandes, M.H. Physical, chemical and in vitro biological profile of chitosan hybrid membrane as a function of organosiloxane concentration. Acta Biomater. 2009, 5, 346-355. [CrossRef] [PubMed]

23. Uragami, T.; Matsuda, T.; Okuno, H.; Miyata, T. Structure of chemically modified chitosan membranes and their characteristics of permeation and separation of ethanol solutions. J. Membr. Sci. 1994, 88, 243-251. [CrossRef] 
24. Lee, D.W.; Lim, C.; Israelachvili, J.N.; Hwang, D.S. Strong adhesion and cohesion of chitosan in aqueous solutions. Langmuir 2013, 29, 14222-14229. [CrossRef] [PubMed]

25. Fowkes, F.M.; Mostafa, M.A. Acid-Base Interactions in Polymer Adsorption. Ind. Eng. Chem. Prod. Res. Dev. 1978, 17, 3-7. [CrossRef]

26. Gandhi, M.R.; Meenakshi, S. Preparation and characterization of silica gel/chitosan composite for the removal of $\mathrm{Cu}(\mathrm{II})$ and $\mathrm{Pb}(\mathrm{II})$. Int. J. Biol. Macromol. 2012, 50, 650-657. [CrossRef] [PubMed]

27. Budnyak, T.; Yanovska, V.T. Chitosan immobilized on silica surface for wastewater treatment. Mater. Sci. 2014, 20, 177-182. [CrossRef]

28. El-Barghouthi, M.; Eftaiha, A.; Rashid, I.; Al-Remawi, M.; Badwan, A. A novel superdisintegrating agent made from physically modified chitosan with silicon dioxide. Drug Dev. Ind. Pharm. 2008, 34, 373-383. [CrossRef] [PubMed]

29. Garbassi, F.; Morra, M.; Occhiello, E. Short-range interactions (Hydrogen, Acid-Base, Covalent). In Polymer Surfaces-From Physics to Technology, Revised and Updated Edition; John Wiley \& Sons Ltd.: Chichester, UK, 1998; pp. 43-45.

30. Briggs, D. Hydrogen bonding. In Handbook of Adhesion, 2nd ed.; Packham, D.E., Ed.; John Wiley \& Sons Ltd.: Chichester, UK, 2005; pp. 230-231.

31. Ogasawara, W.; Shenton, W.; Davis, S.A.; Mann, S. Template mineralization of ordered macroporous chitin-silica composites using a cuttlebone-derived organic matrix. Chem. Mater. 2000, 12, 2835-2837. [CrossRef]

32. Tilburey, G.E.; Patwardhan, S.V.; Huang, J.; Kaplan, D.L.; Perry, C.C. Are Hydroxyl-containing biomolecules important in biosilicification? A model study. J. Phys. Chem. B 2007, 111, 4630-4638. [CrossRef] [PubMed]

33. Mondal, S. Preparation, properties and applications of nanocellulosic materials. Carbohydr. Polym. 2017, 163, 301-316. [CrossRef] [PubMed]

34. Komiyama, M.; Yoshimoto, K.; Sisido, M.; Ariga, K. Chemistry can make strict and fuzzy controls for bio-systems: DNA nanoarchitectonics and cell-macromolecular nanoarchitectonics. Bull. Chem. Soc. Jpn. 2017, 90, 967-1004. [CrossRef]

35. Ariga, K.; Minami, K.; Ebara, M.; Nakanishi, J. What are the emerging concepts and challenges in NANO? Nanoarchitectonics, hand-operating nanotechnology and mechanobiology. Polym. J. 2016, 48, 371-389. [CrossRef]

36. Sezer, A.D.; Cevher, E. Topical drug delivery using chitosan nano- and microparticles. Expert. Opin. Drug Deliv. 2012, 9, 1129-1146. [CrossRef] [PubMed]

37. Onnainty, R.; Onida, B.; Páez, P.; Longhi, M.; Barresi, A.; Granero, G. Targeted chitosan-based bionanocomposites for controlled oral mucosal delivery of chlorhexidine. Int. J. Pharm. 2016, 509, 408-418. [CrossRef] [PubMed]

38. Kosuru, K.R., Sr.; Devi, G., Sr.; Grandhi, V.; Prasan, K.K.; Yasangi, M.K.; Dhanalakshmi, M. Denture care practices and perceived denture status among complete denture wearers. J. Int. Soc. Prev. Community Dent. 2017, 7, 41-45. [CrossRef] [PubMed]

39. Webb, B.C.; Thomas, C.J.; Whittle, T. A 2-year study of Candida-associated denture stomatitis treatment in aged care subjects. Gerodontology 2005, 22, 168-176. [CrossRef] [PubMed]

40. Tay, L.Y.; Jorge, J.H.; Herrera, D.R.; Campanha, N.H.; Gomes, B.P.; Dos Santos, F.A. Evaluation of different treatment methods against denture stomatitis: A randomized clinical study. Oral Surg. Oral Med. Oral Pathol. Oral Radiol. 2014, 118, 72-77. [CrossRef] [PubMed]

41. Vojvodic, D.; Predanic-Gasparac, H.; Brkic, H.; Celecic, A. The bond strength of polymers and metal surfaces using the 'silicoater' technique. J. Oral Rehabil. 1995, 22, 493-499. [CrossRef] [PubMed]

42. Loomans, B.A.; Mesko, M.E.; Moraes, R.R.; Ruben, J.; Bronkhorst, E.M.; Pereira-Cenci, T.; Huysmans, M.C. Effect of different surface treatment techniques on the repair strength of indirect composites. J. Dent. 2017, 59, 18-25. [CrossRef] [PubMed]

(c) 2017 by the authors. Licensee MDPI, Basel, Switzerland. This article is an open access article distributed under the terms and conditions of the Creative Commons Attribution (CC BY) license (http:/ / creativecommons.org/licenses/by/4.0/). 